\title{
Friction and Wear Studies Using Taguchi Method: Application to the Characterization of Carbon-Silicon Carbide Tribological Couples of Automotive Water Pump Seals
}

\author{
Pascal Déprez, ${ }^{1,2}$ Philippe Hivart, ${ }^{1,2}$ Jean François Coutouly, ${ }^{3}$ and Etienne Debarre ${ }^{1,2}$ \\ ${ }^{1}$ Université Lille Nord de France, LGCgE, 59000 Lille, France \\ ${ }^{2}$ UArtois, LAMTI, 62400 Béthune, France \\ ${ }^{3}$ IUT Béthune, CALFA, 62408 Béthune, France
}

Correspondence should be addressed to Pascal Déprez, pascal.deprez@univ-artois.fr

Received 5 August 2009; Revised 18 December 2009; Accepted 28 December 2009

Recommended by João Paulo Davim

An experimental design based on the Taguchi method has been applied to optimize the use of a dynamic sealing element of water pump of automotives combustion engines. A carbon primary ring and a silicon carbide mating ring set up this dynamic sealing element. The aim of this work was to experimentally determine the crossed influence of the primary ring variant, the normal load, the surrounding, the mating ring finishing, and the rotational frequency on the dynamic friction coefficient and on the wear of carbon primary ring-silicon carbide mating ring tribological couples. The coefficient of dynamic friction and the wear depend on the design factors. They are also functions of the interactions between these experimental factors, from the implementation of an experimental design. The results obtained allow the optimal functioning condition to be determined and the best friction couple to be used for a given dynamic sealing application.

Copyright (C) 2009 Pascal Déprez et al. This is an open access article distributed under the Creative Commons Attribution License, which permits unrestricted use, distribution, and reproduction in any medium, provided the original work is properly cited.

\section{Introduction}

Mechanical seals are used throughout industry in numerous rotating equipments such as centrifugal pumps, reactors, mixers, blowers, and compressors. The present investigation concerns the dynamic sealing element of water pump of automotives combustion engines. This mechanical seal consists of two subassemblies, namely, a static head (primary ring) and a dynamic seat (mating ring). The sealing of the primary ring coupled to the mating ring is subjected to pressure and temperature variations and undergoes wear due to friction. The performance of a mechanical seal depends upon a wide range of factors (equipment design, operating conditions, support system, etc.). The selection of the materials of construction of the mechanical seal is particularly important to assure its function and its service life. Different materials (metals, ceramics, elastomers, PTFE, carbon, etc.) were successfully tested $[1,2]$.

The tribological properties of soft materials like carbon against hard mating materials like ceramics are quite unstudied. Nevertheless, due to its lamellar structure, graphite has been known for many years for its low-friction coefficient, even in the case of dry friction [3]. Moreover, carbon is inert, stable, and self lubricating. Concerning the friction and the wear behaviour of carbon against ceramics, it was shown that the friction properties of carbon films are influenced by the hardness of the ceramic slider $[4,5]$, and low and stable friction coefficients were measured [6]. A previous work [7] showed that graphite wear is due to surface fragmentation, crystals being torn off through the lamellas, rather than being chipped off along them. Other tests were carried out on the friction and the wear of carbon on ceramic $[8,9]$. Friction coefficients in the range of 0.1 to 0.2 were determined, and a tendency of a carbon transfer onto the ceramic, producing a dust caused by wear, was noted. There is apparently no direct correlation between the wear rate, the hardness, and the compression stress of the tested carbons. In the case of dry friction, wear is due [8] to material transfer from the worn carbon surface and to the microcrack formation due to surface fatigue. Finally, both processes produce plates. Fragments of these wear plates do not apparently remain 
intact, but they leave the contacted surfaces and they are ground into a fine powder by successive passages of the slider.

In order to minimize the effects of friction and wear, we study a couple of new friction materials. It must be capable of supporting the operating temperature and the chemical environment of the application. It has also to provide a good tribological couple to allow low wear and low friction during operation. This tested couple of materials able to work together to allow the seal to function properly is the couple silicon carbide/carbon material. Silicon carbide is an inert ceramic material characterized by its high hardness, high stiffness, low-thermal expansion, and a good wear resistance. It is an interesting material for extreme tribo-mechanical applications. The carbon material used is a resin impregnated carbon. It is a mixture of amorphous carbon/graphite that has been impregnated with a thermoset resin. Due to good frictional properties, it is the most common type of carbon for mechanical seals used in industry.

In order to improve the performance and reliability of the tested mechanical seal and due to the number of factors, an experimental design based on Taguchi method is carried out. Indeed, the effects of five factors (primary ring variant, normal load, surrounding, mating ring finishing, and the rotational frequency) and of the ten interactions between them on the dynamic friction coefficient and on the wear are studied.

\section{Materials and Methods}

The primary ring and the mating ring are the two most important elementary parts of sealing for which the basic principle is to ensure sealing between the two friction faces, in relative movement, lubricated by a liquid film.

The studied primary rings are moulded by hot compression from a thermohardening resin base and a mixture, with specific proportions of graphite, coke, antimony, and zinc stearate. With the same chemical composition, two carbon materials were obtained from different thermal processes. So, carbon 1 and carbon 2 are carbon materials of a thermohardening resin base which was hot polymerized, and then sterilizated $\left(250-300^{\circ} \mathrm{C}\right)$ to finish the polymerisation. But, for the carbon 1 a later high-temperature process (700$1100^{\circ} \mathrm{C}$ ) was carried out in a neutral atmosphere to avoid oxidation. This process enables the material to become compact and to form a carbon network in the resin. Table 1 summarizes some properties of the two different studied materials. It is interesting to note that the carbon 1 variant is a better thermal conductor and has a lower thermal expansion coefficient than the carbon 2 variant.

The tested mating rings are sintered porous silicon carbide. The part of the porosity is about $10-14 \%$, with pore diameters ranging from 10 to $200 \mu \mathrm{m}$. The chemical composition of the silicon carbide is as follows: $\mathrm{SiC}, 98.5 \%$ minimum; Si free, less than $2000 \mathrm{ppm} ; \mathrm{SiO}_{2}$, less than 2000 ppm; Fe, less than 1000 ppm; other impurities (Al, Ca, $\mathrm{Mg}, \mathrm{K}$, etc.), less than $1000 \mathrm{ppm}$. It should be noted that porous silicon carbide is a good thermal conductor and also has a low-thermal expansion coefficient (Table 1).
TABLe 1: Physical properties of the studied materials.

\begin{tabular}{lccc}
\hline & Carbon 1 & Carbon 2 & Porous silicon carbide \\
\hline $\begin{array}{l}\text { Young modulus } \\
(\mathrm{GPa})\end{array}$ & 25 & 16 & 350 \\
\hline $\begin{array}{l}\text { Thermal } \\
\text { conductivity } \\
\left(\mathrm{W} \cdot \mathrm{m}^{-1} \cdot \mathrm{C}^{-1}\right)\end{array}$ & 20 & 5 & 130 \\
\hline $\begin{array}{l}\text { Thermal } \\
\text { expansion }\end{array}$ & 4 & 14.8 & 4 \\
$\begin{array}{l}\text { coefficient } \\
\left(10^{-6} \cdot \mathrm{C}^{-1}\right)\end{array}$ & 0.21 & 0.21 & 0.25 \\
\hline $\begin{array}{l}\text { Poisson } \\
\text { coefficient }\end{array}$ & 1.85 & 1.77 & 2.82 \\
\hline $\begin{array}{l}\text { Density } \\
\begin{array}{l}\text { Tensile strength } \\
(\mathrm{MPa})\end{array}\end{array}$ & 45 & 28 & 160 \\
\hline $\begin{array}{l}\text { Compressive } \\
\text { strength }(\mathrm{MPa})\end{array}$ & 180 & 100 & 1500 \\
\hline $\begin{array}{l}\text { Brinell hardness } \\
(\text { daN/mm }\end{array}$
\end{tabular}

The arithmetic roughness of the primary ring and the mating ring is a function of the final lapping applied to the surface of these parts. A final lapping period followed by glazing $(3 \mu \mathrm{m})$ is carried out on the primary ring while the mating ring undergoes another final lapping period (boron $400)$ or a glazing $(3 \mu \mathrm{m})$.

Figure 1 shows the set-up for the friction test implemented during this study and the geometry and dimensions of the mating ring and the primary ring of the studied water pump of automotives combustion engines.

The tribometer used was studied in order to carry out friction tests on a couple of materials, without sensitive differential pressure pairs of materials, in liquid-surrounding air condition. The tank of the tribometer is assembled to turn between two bearings. The friction ring is assembled onto the the bottom of the tank. The tank contains about 1 liter of cooling liquid composed of $65 \%$ abelledesd water and 35\% glycol. This glycol-based coolant has also the function of a lubricant. An electronic torque-meter, linked abelle the tank and a fixed part of the machine, allows the measurement of the resisting torque. During the test, the temperature of the liquid in the tank and the temperature measured at $0.5 \mathrm{~mm}$ from the friction face are taken by using thermocouples. The rotational speed of the primary ring is raised through the use of a cog wheel and a sensor. These measurements are carried out at a frequency of $50 \mathrm{~Hz}$ by means of a data-acquisition board. An average of the measurements is taken and recorded every second.

The dynamic friction coefficient stabilized $(R 1)$ and the wear $(R 2)$ of the carbon primary rings have been recorded after testing the materials for 10 hours. During the friction test, the temperature maximal ( $R 3)$, five abelledes under the friction surface of the primary ring, was also recorded. 


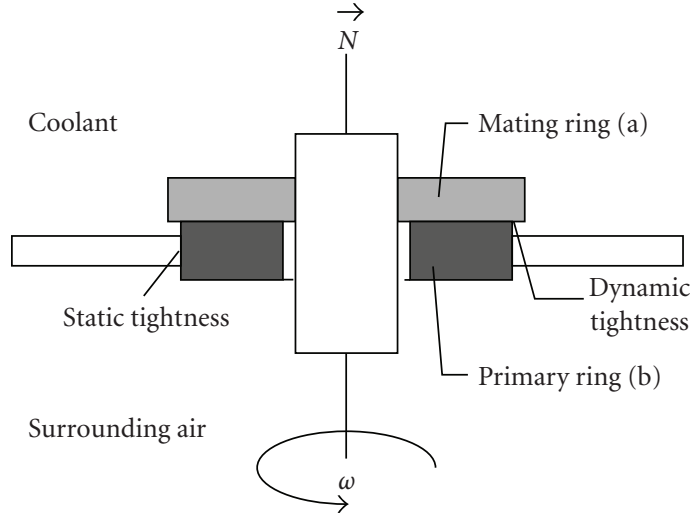

(a)

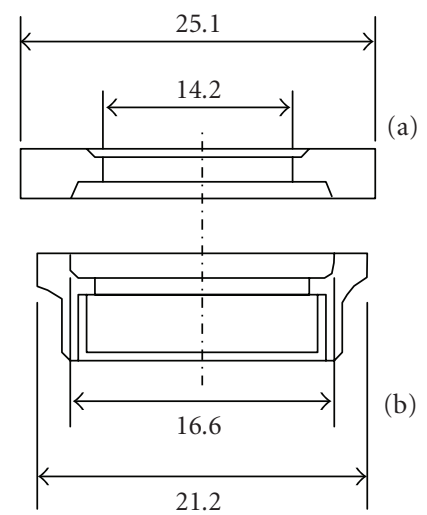

(b)

FIGURE 1: Friction test set-up and geometry and dimensions of the mating ring (a) and the primary ring (b).

This study is conducted with the Taguchi method by means of "orthogonal array" experiments $[10,11]$. This method based on orthogonal array experiments gives much reduced variance for the experiment with optimum settings of control factors. The Taguchi approach provides also more complete interaction information than typical fractional factorial designs. In order to investigate the friction $(R 1)$, the wear $(R 2)$, and the temperature $(R 3)$, a suitable orthogonal array $\left[\mathrm{L}_{16}\left(2^{15}\right)\right]$ was selected for carrying out the experimentation. Five factors are considered. Each of them has two levels: the material of the primary ring (level 1: carbon 1; level 2: carbon 2), the surface finishing of the mating ring (level 1: boron 400; level 2: glazing $3 \mu \mathrm{m}$ ), the normal load (level 1: $1 \mathrm{daN}$; level 2: $5 \mathrm{daN}$ ), the surrounding (level 1: dry; level 2: lubricated), and the rotational frequency (level 1: $50 \mathrm{rad} \cdot \mathrm{s}^{-1}$; level 2: $\left.400 \mathrm{rad} \cdot \mathrm{s}^{-1}\right)$. These factors and levels used in the orthogonal analysis and the 10 combinations of these 5 factors, arranged according to the 15 columns of the orthogonal array $\mathrm{L}_{16}\left(2^{15}\right)$, are shown in Table 2. Instead of having to test the 32 possible combinations like the factorial design, the Taguchi method tests only 16 . This allows for the collection of the necessary data to determine which factors and interactions most affect friction, wear, and temperature with a minimum amount of experimentation, thus saving time and resources. The 16 various tests, according to the 16 lines of the orthogonal array $\mathrm{L}_{16}\left(2^{15}\right)$ which corresponds to $2^{5}$ factorial experiment design, were realised. An analysis of variance on the collected data from the Taguchi design of experiments can be used to identify significant factors and interactions between the factors. A predictive mathematical model can also be developed, using nonlinear regression method, to optimize the performance outputs $(R 1, R 2, R 3)$.

\section{Factor Levels for Each Studied Factor:}

F1: primary ring variant (level 1: carbon 1, level 2: carbon 2),

F2: normal load (level 1: 1 daN, level 2: 5 daN),

F3: surrounding (level 1: dry, level 2: lubricated),
F4: mating ring finishing (level 1: $3 \mu \mathrm{m}$, level 2: boron 400),

F5: rotational frequency: (level 1: $50 \mathrm{rad} / \mathrm{s}$, level 2: $400 \mathrm{rad} / \mathrm{s})$.

\section{Combinations between Factors:}

$I x-y$ : interaction column between the two factors allocated to columns $x$ and $y$.

\section{Experimental Results:}

$R 1$ : coefficient of dynamic friction after 10 hours of friction test,

$R 2$ : wear of the carbon primary ring $(\mu \mathrm{m})$ after 10 hours of friction test,

R3: temperature maximal $\left({ }^{\circ} \mathrm{C}\right)$ measured during the friction test, five millimetres under the friction surface of the primary ring.

Figure 2 shows the linear graph associated with the orthogonal array $\mathrm{L}_{16}\left(2^{15}\right)$. This linear graph allows to affect the interactions (level 2) between the five studied factors. For example, it shows two points abelled 1 and 2, indicating that two factors can be assigned to columns 1 and 2 of the orthogonal array $\mathrm{L}_{16}\left(2^{15}\right)$. The line 3 connecting them indicates that the interaction between columns 1 and 2 is present in column 3 .

\section{Results and Discussion}

For the studied process to be optimized, five control factors which directly decide the value of the coefficient of dynamic friction and of the wear are considered. Due to better stability, the average effects of these studied factors are established after 10 hours of friction. The Taguchi method based on "orthogonal array" experiments gives much reduced variance for the experiment with "optimum settings" of control factors. The "orthogonal array" experiments help also in data 
TABLE 2: Taguchi orthogonal array $\mathrm{L}_{16}\left(2^{15}\right)$.

\begin{tabular}{ccccccccccccccccccc}
\hline$F 2$ & $F 5$ & $I 1-2$ & $F 1$ & $I 1-4$ & $I 2-4$ & $I 8-15$ & $F 4$ & $I 1-8$ & $I 2-8$ & $I 4-15$ & $I 4-8$ & $I 2-15$ & $I 1-15$ & $F 3$ & $R 1$ & $R 2$ & $R 3$ \\
\hline 1 & 1 & 1 & 1 & 1 & 1 & 1 & 1 & 1 & 1 & 1 & 1 & 1 & 1 & 1 & 0.69 & 1 & 78 \\
1 & 1 & 1 & 1 & 1 & 1 & 1 & 2 & 2 & 2 & 2 & 2 & 2 & 2 & 2 & 0.41 & 2 & 27 \\
1 & 1 & 1 & 2 & 2 & 2 & 2 & 1 & 1 & 1 & 1 & 2 & 2 & 2 & 2 & 0.30 & 4 & 32 \\
1 & 1 & 1 & 2 & 2 & 2 & 2 & 2 & 2 & 2 & 2 & 1 & 1 & 1 & 1 & 0.39 & 4 & 65 \\
1 & 2 & 2 & 1 & 1 & 2 & 2 & 1 & 1 & 2 & 2 & 1 & 1 & 2 & 2 & 0.42 & 2 & 52 \\
1 & 2 & 2 & 1 & 1 & 2 & 2 & 2 & 2 & 1 & 1 & 2 & 2 & 1 & 1 & 0.18 & 16 & 142 \\
1 & 2 & 2 & 2 & 2 & 1 & 1 & 1 & 1 & 2 & 2 & 2 & 2 & 1 & 1 & 0.26 & 23 & 172 \\
1 & 2 & 2 & 2 & 2 & 1 & 1 & 2 & 2 & 1 & 1 & 1 & 1 & 2 & 2 & 0.74 & 2 & 48 \\
2 & 1 & 2 & 1 & 2 & 1 & 2 & 1 & 2 & 1 & 2 & 1 & 2 & 1 & 2 & 0.26 & 3 & 35 \\
2 & 1 & 2 & 1 & 2 & 1 & 2 & 2 & 1 & 2 & 1 & 2 & 1 & 2 & 1 & 0.55 & 26 & 194 \\
2 & 1 & 2 & 2 & 1 & 2 & 1 & 1 & 2 & 1 & 2 & 2 & 1 & 2 & 1 & 0.43 & 21 & 137 \\
2 & 1 & 2 & 2 & 1 & 2 & 1 & 2 & 1 & 2 & 1 & 1 & 2 & 1 & 2 & 0.31 & 70 & 46 \\
2 & 2 & 1 & 1 & 2 & 2 & 1 & 1 & 2 & 2 & 1 & 1 & 2 & 2 & 1 & 0.62 & 39 & 473 \\
2 & 2 & 1 & 1 & 2 & 2 & 1 & 2 & 1 & 1 & 2 & 2 & 1 & 1 & 2 & 0.41 & 5 & 139 \\
2 & 2 & 1 & 2 & 1 & 1 & 2 & 1 & 2 & 2 & 1 & 2 & 1 & 1 & 2 & 0.37 & 6 & 125 \\
2 & 2 & 1 & 2 & 1 & 1 & 2 & 2 & 1 & 1 & 2 & 1 & 2 & 2 & 1 & 0.57 & 289 & 535 \\
\hline
\end{tabular}

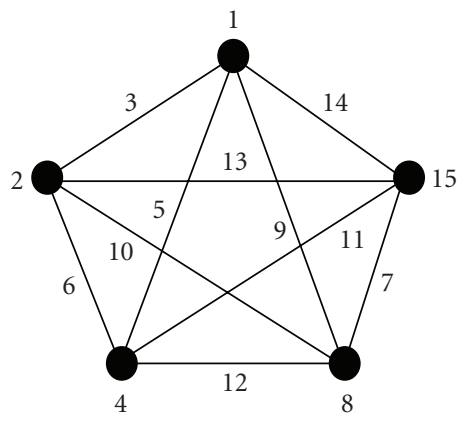

FIgURE 2: Linear graph associated with the orthogonal array $\mathrm{L}_{16}\left(2^{15}\right)$.

analysis and prediction of optimum results. For that purpose, the following formulae will be considered.

The middle effect of factor $A$ at the level $i$ is

$E_{A i}=$ (average of the responses $R$ when the factor $A$ is at the level $i)-R_{\text {avg }}$

with $R_{\mathrm{avg}}$ as the general average of the response $R$.

The interaction effect of factor $A$ at level $i$ and factor $B$ at level $j$ is

$E_{A i B j}=$ (average of responses $R$ when factor $A$ is at level $i$ and $B$ at level $j)-E_{A i}-E_{B j}-R_{\text {avg }}$.

The squares sum of factor $A$ is:

$$
S_{A}=\left(\frac{N}{n_{A}}\right) \sum_{i=1}^{n_{A}}\left(E_{A i}\right)^{2}
$$

with $N=16$ (number of tests) and $n_{A}$ the number of factor $A$ levels. i:

The squares sum of the interaction factor $A$ and factor $B$

$$
S_{A B}=\left(\frac{N}{n_{A}} \cdot n_{B}\right)_{i, j=1}^{n_{A}, n_{B}}\left(E_{A i B j}\right)^{2} .
$$

The percentage of contribution of factor $A$ on the response is

$$
\% A=\left(\frac{S_{A}}{S_{\text {total }}}\right) \cdot 100 .
$$

The percentage of contribution of the interaction factor $A$ and factor $B$ on the response is

$$
\% A B=\left(\frac{S_{A B}}{S_{\text {total }}}\right) \cdot 100 .
$$

3.1. Study of the Dynamic Friction Coefficient. Figure 3 shows the main effects of the five studied factors on the coefficient of dynamic friction $(R 1)$ after 10 hours of friction test. The level change of factors induces a variation of the value of this coefficient.

The degree of the effect of a factor is indicated by plots, as shown in Figure 3. The larger the deviation from horizontal, the stronger the effect of the factor. The most significant factor influencing the coefficient of dynamic friction after 10 hours of friction test is the environment. A decrease of this coefficient (about 13\%) in a lubricated environment is noted.

On the other hand, the transitions from carbon 1 to carbon 2 for the primary ring, from $5 \mathrm{daN}$ to $1 \mathrm{daN}$ for the normal load, from a boron 400 finish to a glazing $3 \mu \mathrm{m}$ finish for the mating ring, and from $400 \mathrm{rad} / \mathrm{s}$ to $50 \mathrm{rad} / \mathrm{s}$ for the rotational frequency do not strongly influence the decrease of the coefficient of dynamic friction after 10 hours of friction test (less than 6.5\%). 


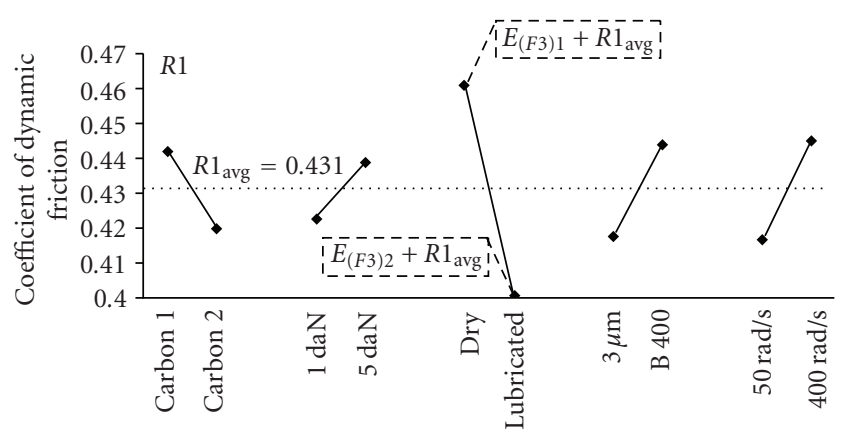

FIGURE 3: Main effects on the coefficient of dynamic friction $(R 1)$.

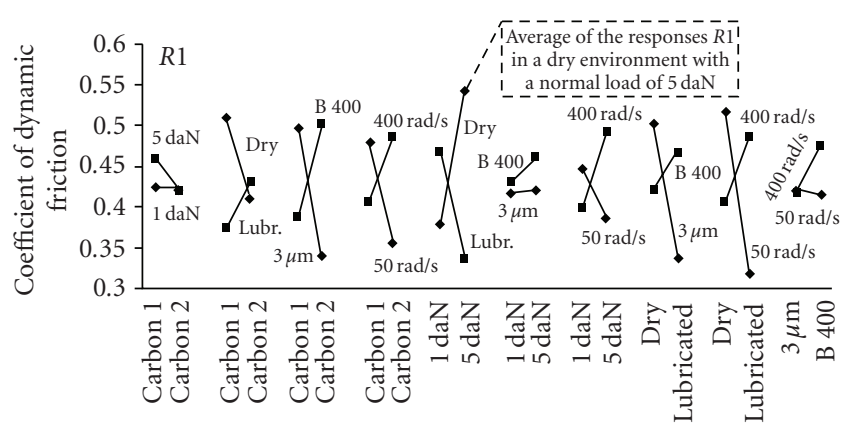

FIGURE 4: Interaction effects on the coefficient of dynamic friction $(R 1)$.

However, it is interesting to note that this coefficient is higher with the carbon 1 primary ring material than with the carbon 2. For the couple carbon 1-porous silicon carbide, carbon traces in the porosities and on the friction face of the mating ring are rarely seen; with the couple carbon 2-porous silicon carbide, deposits and traces of carbon are nearly always observed on the porous silicon carbide mating ring. This phenomenon is probably due to a lower hardness for the carbon 2 with regard to the carbon 1 . Also, the porosities tend to be closed by the carbon. The lubricating quality of the graphite, the presence of graphite in the porosities of the carbide, and the traces of graphite on the friction surface of the mating ring explain the decrease of the coefficient of dynamic friction after 10 hours of friction test with the carbon 2.

If the effect of a factor is influenced by the level change of another factor, there is a phenomenon of interaction between these two factors. Figure 4 shows that the effect of the 5 studied factors is influenced by the level change of the other factors (not parallel segments). Indeed, both segments which represent each of the 10 interactions are not parallel. They translate different variations of responses and so show that the interactions of level 2 between the design parameters are significant.

The degree of interaction between two factors is indicated by plots, as shown in Figure 4. The larger the deviation from parallel, the stronger the interaction. The degree of interaction can be calculated from an analysis of variance, which is described in paragraph 3.3.
The most significant interactions are the interactions between primary ring material/mating ring finishing, normal load/surrounding and surrounding/rotational frequency.

It is interesting to note that the effect of the primary ring material on the coefficient of dynamic friction after 10 hours of friction test is compensated by the effect of the normal load and of the relative speed.

In the case of carbon 2 primary ring material, the coefficient of dynamic friction after 10 hours of friction test is the same with a normal load of $1 \mathrm{daN}$ or $5 \mathrm{daN}$. The work of Golubiev [12] explains this phenomenon. During his attempts to measure the pressure in the interface of dynamic waterproof guards, he observed the presence of microhumps due to thermal conductivities and thermal expansion coefficients as well as the locally different frictional temperatures (carbon 2 is a lower thermal conductor and has a better thermal expansion coefficient than the carbon 1). With intersecting contact pressure, owing to the dilatation of the carbon produced by the heating which is a function of the speed, the carbon face is pressed in the pores due to its low coefficient of elasticity. In case of higher load, the carbon particles are cut inducing the decrease of the coefficient of dynamic friction.

The interaction between the normal load and the environment shows that the effect of the load is compensated by the environment. In the case of dry running, the coefficient of dynamic friction after 10 hours of friction test increases proportionally with the load. However, in a lubricated environment, it diminishes when the load increases. The cavities formed from the pores create greasing reserves and zones of locally limited pressure. With increasing contact pressure, the antagonistic carbon face is pressed into the pores, and ejects the coolant (Figure 5).

Taguchi method allowed to bring to light the relative contributions of the design factors and of their interactions on the coefficient of dynamic friction of the studied carbonsilicon carbide tribological couple.

3.2. Study of the Wear. Figure 6 shows the main effects of the five studied factors on the wear $(R 2)$ of the carbon primary ring after 10 hours of friction test. The obtained results show that these factors have an important influence on the measured wear.

With carbon 1, having a higher hardness than carbon 2 , the fact of using a carbon 1 primary ring in the place of a carbon 2 induces a decrease of the wear of about $58 \%$. The most significant factor influencing the carbon primary ring wear is the normal load applied on the dynamic sealing element. With regard to a normal load of $5 \mathrm{daN}$, a normal load of $1 \mathrm{daN}$ induces a significant decrease of the wear of about $88 \%$. A lubricated environment makes the wear of the carbon primary ring decrease about $77 \%$. Also, the transition from a boron 400 finishing to a glazing $3 \mu \mathrm{m}$ finishing for the silicon carbide mating ring induces a decrease of the wear of about $76 \%$. Finally, with regard to a rotational frequency of $400 \mathrm{rad} / \mathrm{s}$, a rotational frequency of $50 \mathrm{rad} / \mathrm{s}$ induces a decrease of the wear of about $65 \%$. 


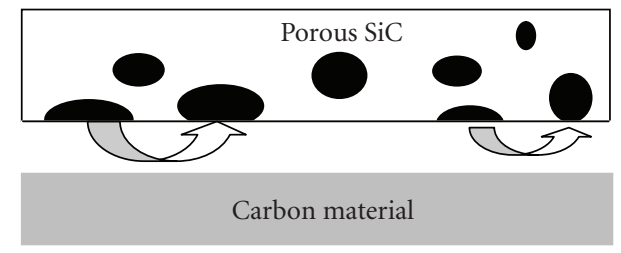

(a)

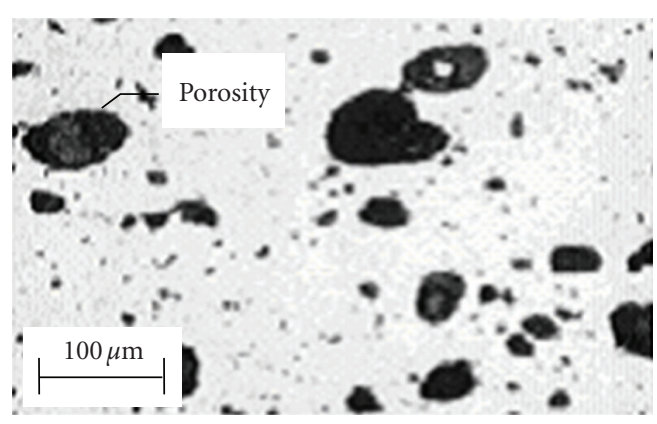

(b)

FIGURE 5: (a) Drainage of the lubricant from a cavity to another one. (b) micrograph of the porous silicon carbide.

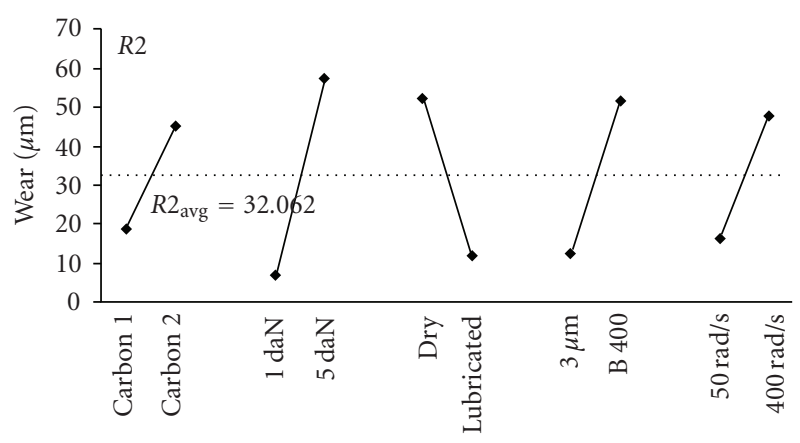

FIGURE 6: Main effects on the wear (R2).

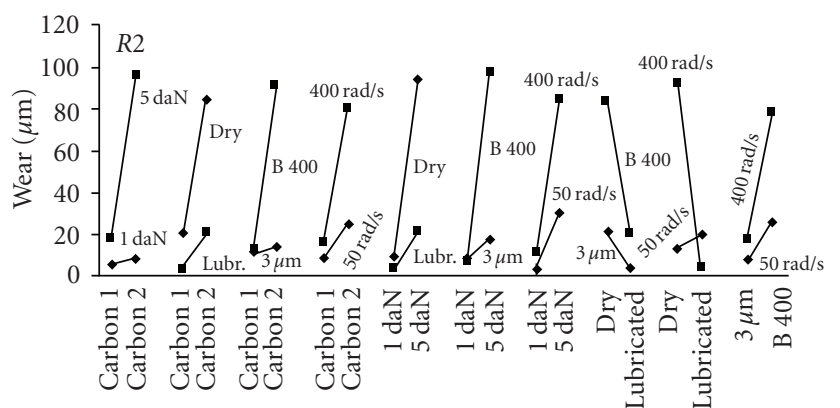

FIGURE 7: Interaction effects on the wear $(R 2)$.
The roughness of the mating ring as well as the surrounding influence the wear of the carbon [13]. The values of wear for dry and limited frictional states are compared by Holm [14]. According to Holm, a difference from 1 to 10 can be observed. In the case of dry friction, the influence of the material is strongly in evidence and the values for the wear can extend over two orders of magnitude. It was noticed that the coefficient of friction does not ever increase in proportion to the wear [15-17].

Figure 7 shows that the interaction effects of the design factors on the wear of the carbon primary ring after 10 hours of friction test are influenced by the level change of the other factors (not parallel segments). The most significant interactions are the interactions between primary ring variant/surrounding, normal load/surrounding, normal load/mating ring finishing, and surrounding/rotational frequency.

For the carbon 1, the wear after 10 hours of friction test is weakly influenced by the normal load, the surrounding, the mating ring finishing, and the rotational frequency. On the other hand, with carbon 2, this wear is strongly influenced by the level change of the other factors. The lower hardness of carbon 2 compared to carbon 1 can explain these results.

For a normal load of $1 \mathrm{daN}$, the wear is not influenced by the level change of the other factors. On the other hand, for a normal load of $5 \mathrm{daN}$, the wear is strongly influenced by their level change. There is an increasing effect of the temperature with the normal contact load. An increase in the frictional pressure is mainly related to an increase in the temperature of the waterproof interface and thus the effects are manifested as wear. The increase in temperature often causes a decrease in the resistance and in the hardness. It can also induce the evaporation of the lubricating film in the waterproof interface. In dry friction test, the wear of different materials from ceramic to carbon rapidly adopts significant values with increasing temperature. In dry or in lubricated friction test, this increase in temperature induces a risk of creating cracks, which in turn increase the wear [18]. This can result from mechanical or thermal overloads, from a dry running or a lower cooling, from variations of pressure, from high speeds or alterations of the conditions of the interface.

The graph of the interaction between the surrounding and the rotational frequency (Figure 7) shows that in a lubricated surrounding, the wear is more important with the smallest rotational frequency, which is $50 \mathrm{rad} / \mathrm{s}$. But, according to Archard [19], an increase in wear is proportional to an increase in the frictional speed. This is true, provided that no additional hydrodynamic effect is produced. According to the measurements made by Paxton and Shobert [7] and by Wisander and Johnson [20], the wear can present a tendency towards being stationary or descending as a function of speed. This phenomenon depends strongly upon the couple of materials and the lubricating fluid. 


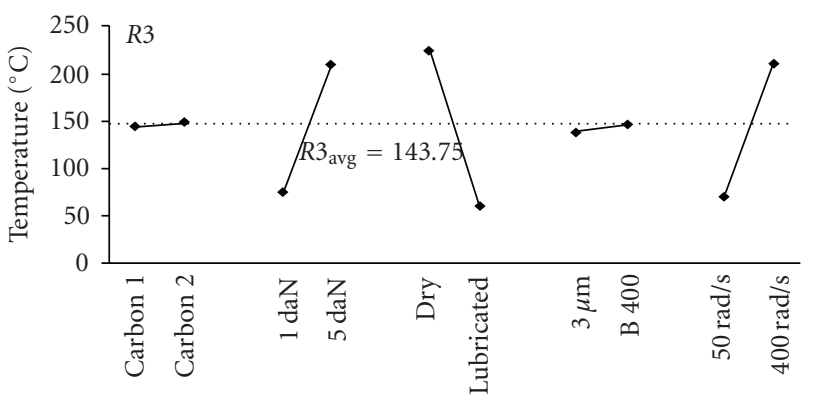

Figure 8: Influence of the studied factors on the temperature maximal measured during the friction test, five millimeters under the friction surface of the primary ring $(R 3)$.

3.3. Study of the Temperature. The temperature maximal (R3) obtained during the friction test, five millimeters under the friction surface of the primary ring, is measured (Table 2). From the average effects graphs of the five studied factors (Figure 8), it is shown that the normal load, the surrounding and the rotational strongly frequency influence this temperature. The transitions from $5 \mathrm{daN}$ to $1 \mathrm{daN}$ for the normal load, from dry to lubricated surrounding, and from $400 \mathrm{rad} / \mathrm{s}$ to $50 \mathrm{rad} / \mathrm{s}$ for the rotational frequency induce a significant decrease of this temperature. On the other hand, the primary ring variant and the mating ring finishing do not influence it significantly. It is interesting to note that different thermal conductivity coefficient, the temperature maximal measured, under the same parametric conditions, is equivalent with the carbon 1 and the carbon 2 primary ring material.

The increase in temperature of the dynamic sealing element induces a risk of thermal cracks. And so, it reduces its service life. Control of thermal cracking is of a great importance to ensure a desired service life time and function of the studied dynamic sealing element. In the present study, primary ring cracks have been experimentally reproduced (Figure 9).

Factors affecting the initiation of thermal cracks as well as the wear of the carbon primary ring can result from mechanical or thermal overloads, from dry running or a lower cooling, from variations of pressure, from high speeds, or alteration of the interface. It can be noticed that no thermal crack has been observed in lubricated regime.

3.4. Modelling and Analysis of the Variance. The prediction of the coefficient of dynamic friction and the wear models for the studied carbon-silicon carbide tribological couple were developed based on the following matrix model:

$$
\begin{aligned}
M= & R_{\mathrm{avg}} \\
& +\left[+E_{A 1}-E_{A 2}\right][A] \\
& +\cdots
\end{aligned}
$$

$$
\begin{aligned}
& +{ }^{t}[A]\left[\begin{array}{ll}
+E_{A 1 B 1} & -E_{A 1 B 2} \\
-E_{A 2 B 1} & +E_{A 2 B 2}
\end{array}\right][B] \\
& +\cdots \\
& + \text { RES }
\end{aligned}
$$

with $M$ : calculated response, $R_{\text {avg }}$ : general average of the response $R,[A]$ : Vector "level indicator" of the factor $A$, $[A]=\left[\begin{array}{l}1 \\ 0\end{array}\right]$ for $A$ at level 1 or $\left[\begin{array}{l}0 \\ 1\end{array}\right]$ at level $2, t[A]$ : Vector transposed of vector $[A]$, and Res: Residual term.

The matrix models of the coefficient of dynamic friction and the wear after 10 hours of friction test are established by taking into account the five studied factors, as well as the ten interactions between these factors. The two matrix models $(M 1, M 2)$ allow determining the best combination among 32 possible to minimize the coefficient of dynamic friction $(R 1)$ and the wear $(R 2)$. From the matrix model $M 1$, the combination of factors minimizing the coefficient of dynamic friction after 10 hours of friction test is

(i) primary ring material $(F 1)$ : carbon 2 ,

(ii) normal load (F2): $5 \mathrm{daN}$,

(iii) surrounding (F3): lubricated,

(iv) mating ring finishing ( $F 4): 3 \mu \mathrm{m}$ glazing,

(v) rotational frequency (F5): $50 \mathrm{rad} / \mathrm{s}$,

the combination of factors minimizing the wear after 10 hours of friction test is, according to the matrix model $M 2$,

(i) primary ring material $(F 1)$ : carbon 1 or carbon 2 ,

(ii) normal load (F2): $1 \mathrm{daN}$,

(iii) surrounding (F3): lubricated,

(iv) mating ring finishing (F4): $3 \mu \mathrm{m}$ glazing,

(v) rotational frequency $(F 5): 400 \mathrm{rad} / \mathrm{s}$.

The influence of carbon material on the wear is not significant.Indeed, with a normal load of $1 \mathrm{daN}$, in a lubricated environment, with a $3 \mu \mathrm{m}$ glazing mating ring finishing and 


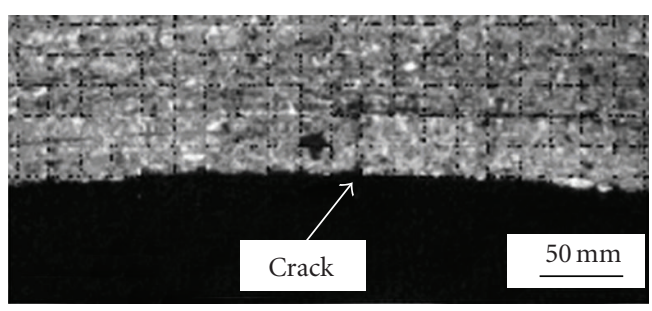

(a)

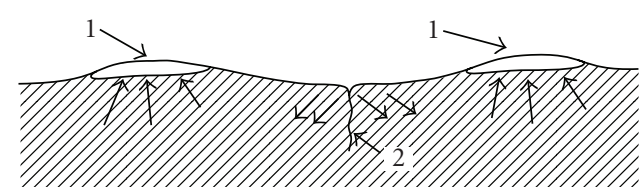

1. Increase of the temperature at the friction surface 2. Crack by thermal expansion

(b)

Figure 9: (a) surface of the primary ring crack; (b) crack by thermal dilatation. Parametric conditions of the friction test: carbon 1 (primary ring variant), $5 \mathrm{daN}$ (normal load), dry (surrounding), $3 \mu \mathrm{m}$ (mating ring finishing), $400 \mathrm{rad} / \mathrm{s}$ (rotational frequency). Temperature maximal measured during the test: $473^{\circ} \mathrm{C}$.

a rotational frequency of $400 \mathrm{rad} / \mathrm{s}$, the use of carbon 1 or carbon 2 mating ring changes the wear rate less than $0.3 \%$.

$$
\begin{aligned}
& M 1=0.431 \\
& +\left[\begin{array}{ll}
+0.011 & -0.011
\end{array}\right][F 1] \\
& +[-0.008+0.008][F 2] \\
& +\left[\begin{array}{ll}
+0.03 & -0.03
\end{array}\right][\text { F3 }] \\
& +[-0.013+0.013][F 4] \\
& +[-0.014+0.014][F 5] \\
& +{ }^{t}[F 1]\left[\begin{array}{ll}
-0.009 & +0.009 \\
+0.009 & -0.009
\end{array}\right][F 2] \\
& +{ }^{t}[F 1]\left[\begin{array}{cc}
+0.037 & -0.037 \\
-0.037 & +0.037
\end{array}\right][F 3] \\
& +{ }^{t}[F 1]\left[\begin{array}{ll}
+0.067 & -0.067 \\
-0.067 & +0.067
\end{array}\right][F 4] \\
& +{ }^{t}[F 1]\left[\begin{array}{ll}
+0.048 & -0.048 \\
-0.048 & +0.048
\end{array}\right][F 5] \\
& +{ }^{t}[F 2]\left[\begin{array}{ll}
-0.073 & +0.073 \\
+0.073 & -0.073
\end{array}\right][F 3] \\
& +{ }^{t}[F 2]\left[\begin{array}{ll}
+0.006 & -0.006 \\
-0.006 & +0.006
\end{array}\right][F 4] \\
& +{ }^{t}[F 2]\left[\begin{array}{cc}
+0.037 & -0.037 \\
-0.037 & +0.037
\end{array}\right][F 5] \\
& +{ }^{t}[F 3]\left[\begin{array}{ll}
+0.051 & -0.051 \\
-0.051 & +0.051
\end{array}\right][F 4]
\end{aligned}
$$

$$
\begin{aligned}
& +{ }^{t}[F 3]\left[\begin{array}{cc}
+0.067 & -0.067 \\
-0.067 & +0.067
\end{array}\right][F 5] \\
& +{ }^{t}[F 4]\left[\begin{array}{ll}
+0.015 & -0.015 \\
-0.015 & +0.015
\end{array}\right][F 5] \\
& + \text { RES, } \\
& M 2=32.062 \\
& +[-13.262+13.262][F 1] \\
& +[-25.312+25.312][F 2] \\
& +\left[\begin{array}{ll}
+20.313 & -20.313
\end{array}\right][\text { F3 }] \\
& +[-19.687+19.687][F 4] \\
& +[-15.687+15.687][\text { F5 }] \\
& +{ }^{t}[F 1]\left[\begin{array}{ll}
+11.762 & -11.762 \\
-11.762 & +11.762
\end{array}\right][F 2] \\
& +{ }^{t}[F 1]\left[\begin{array}{ll}
-18.613 & +18.613 \\
+18.613 & -18.613
\end{array}\right][F 3] \\
& +{ }^{t}[F 1]\left[\begin{array}{ll}
+12.137 & -12.137 \\
-12.137 & +12.137
\end{array}\right][F 4] \\
& +{ }^{t}[F 1]\left[\begin{array}{ll}
+4.887 & -4.887 \\
-4.887 & +4.887
\end{array}\right][F 5] \\
& +{ }^{t}[F 2]\left[\begin{array}{ll}
-18.263 & +18.263 \\
+18.263 & -18.263
\end{array}\right][F 3] \\
& +{ }^{t}[F 2]\left[\begin{array}{ll}
+20.437 & -20.437 \\
-20.437 & +20.437
\end{array}\right][F 4] \\
& +{ }^{t}[F 2]\left[\begin{array}{ll}
+11.687 & -11.687 \\
-11.687 & +11.687
\end{array}\right][F 5]
\end{aligned}
$$




$$
\begin{aligned}
& +{ }^{t}[F 3]\left[\begin{array}{ll}
-11.688 & +11.688 \\
+11.688 & -11.688
\end{array}\right][F 4] \\
& +{ }^{t}[F 3]\left[\begin{array}{ll}
-23.688 & +23.688 \\
+23.688 & -23.688
\end{array}\right][F 5] \\
& +{ }^{t}[F 4]\left[\begin{array}{ll}
+10.562 & -10.562 \\
-10.562 & +10.562
\end{array}\right][F 5] \\
& + \text { RES }
\end{aligned}
$$

with $M 1$ : calculated coefficient of dynamic friction, $M 2$ : calculated wear, $[F x]$ : Vector "level indicator" of the factor $F x,{ }^{t}[F x]:$ Vector transposed of vector $[F x]$, and Res: Residual term.

An analysis of the variance allows determining the percentage of contribution of every factor and interaction on the coefficient of dynamic friction and on the wear after 10 hours of friction test. These percentages of contribution of the five studied factors and of their interactions are shown in Table 3.

The percentages of contribution on the coefficient of dynamic friction reveal that the influence of the five studied factors is weak. On the other hand, these factors acting in interaction with another factor have a significant influence on the coefficient of dynamic friction after 10 hours of friction test. This analysis of the variance confirms that the most significant interactions are the interactions between primary ring material/mating ring finishing, normal load/surrounding, and surrounding/rotational frequency.

Table 3 shows that three factors and four interactions have a significant influence on the wear, with a percentage of contribution superior to $7 \%$.

\section{Conclusion}

The use of a couple of different materials is one engineering technique used in the tribological process of critical components as dynamic sealing element of water pump of automotives combustion engines. Due to the number of variables affecting the service life of the components, surfaces friction is a complex process in itself. In order to investigate the influence of majors factors on the coefficient of dynamic friction and the wear of carbon-silicon carbide tribological couples, the Taguchi method was applied.

The knowledge obtained in the present study allows to optimize a new couple of materials for dynamic sealing applications. This study investigated the effects of five factors and their interactions (level 2) on the coefficient of dynamic friction and the wear of carbon-silicon carbide couples, to determine the optimal conditions and the best friction couple to use for dynamic sealing applications. Regarding the coefficient of dynamic friction, factors such as the variant of the primary ring, the mating ring finishing, the speed, and the normal load have little influence. On the other hand, a significant decrease in the coefficient
TABLE 3: Percentage of contribution of every factor and interaction on the coefficient of dynamic friction $(R 1)$ and on the wear $(R 2)$ after 10 hours of friction test.

\begin{tabular}{lcc}
\hline Factors & $R 1$ & $R 2$ \\
\hline primary ring variant & $0.49 \%$ & $3.72 \%$ \\
normal load & $0.26 \%$ & $13.57 \%$ \\
surrounding & $3.68 \%$ & $8.74 \%$ \\
mating ring finishing & $0.69 \%$ & $8.21 \%$ \\
rotational frequency & $0.8 \%$ & $5.21 \%$ \\
\hline Interactions & & \\
\hline primary ring variant/normal load & $0.39 \%$ & $2.93 \%$ \\
primary ring variant/surrounding & $5.63 \%$ & $7.34 \%$ \\
primary ring variant/mating ring finishing & $18.43 \%$ & $3.12 \%$ \\
primary ring variant/rotational frequency & $9.47 \%$ & $0.5 \%$ \\
normal load/surrounding & $22.33 \%$ & $7.06 \%$ \\
normal load/mating ring finishing & $0.15 \%$ & $8.85 \%$ \\
normal load/rotational frequency & $5.63 \%$ & $2.89 \%$ \\
surrounding/mating ring finishing & $10.69 \%$ & $2.89 \%$ \\
surrounding/rotational frequency & $18.43 \%$ & $11.88 \%$ \\
mating ring finishing/rotational frequency & $0.93 \%$ & $2.36 \%$ \\
\hline
\end{tabular}

is observed in a lubricated surrounding. Also, the interactions between primary ring material/mating ring finishing, normal load/surrounding, and surrounding/rotational frequency influence strongly the coefficient of dynamic friction. Concerning the wear of the carbon primary ring, the five studied factors and the interactions between primary ring variant/surrounding, normal load/surrounding, nor$\mathrm{mal}$ load/mating ring finishing, and surrounding/rotational frequency have a significant influence. Two matrix models allowed determining the combination of factors minimizing the coefficient of dynamic friction and the wear of the studied tribological couple. With these last ones not being minimal in the same conditions, the choice of these factors results from a compromise dependent on the use.

For the studied dynamic sealing element, lubricant is used to separate the carbon primary ring from the porous silicon carbide mating ring. As a result, one can increase the capacity for specific load and reduce wear. The lubricant and air make up the surroundings of functioning of the studied system. It could be interesting to consider the influence of exterior elements such as the dust and the grease. Indeed, in interaction with the environment of functioning, these last ones can influence the wear behavior of the tribological system. These interactions can have very different forms: air/coolant, tribo-oxidation/lubrication, abrasion/mating ring-primary ring, chemical reaction/mating ring-primary ring, and so forth.

\section{References}

[1] API standard 682, Pumps-Shaft Sealing Systems: Centrifugal and Rotary Pumps, American Petroleum Institute, Washington, DC, USA, 3rd edition, 2004. 
[2] M. Huebner, "Material selection for mechanical seals," in Proceedings of the 22nd International Pump Users Symposium, Houston, Tex, USA, February-March 2005.

[3] A. G. Khurshudov, M. Olsson, and K. Kato, "Tribology of unlubricated sliding contact of ceramic materials and amorphous carbon," Wear, vol. 205, no. 1-2, pp. 101-111, 1997.

[4] A. Gangopadhyay, "Mechanical and tribological properties of amorphous carbon films," Tribology Letters, vol. 5, no. 1, pp. 25-39, 1998.

[5] B. Carroll, Y. Gogotsi, A. Kovalchenko, A. Erdemir, and M. J. McNallan, "Effect of humidity on the tribological properties of carbide-derived carbon (CDC) films on silicon carbide," Tribology Letters, vol. 15, no. 1, pp. 51-55, 2003.

[6] H. Liu, A. Tanaka, and T. Kumagai, "Influence of sliding mating materials on the tribological behavior of diamond-like carbon films," Thin Solid Films, vol. 352, no. 1-2, pp. 145-150, 1999.

[7] R. Paxton and J. Shobert, "Testing carbon for seals and bearings," American Society of Lubrication Engineers, vol. 9, pp. 27-33, 1961.

[8] P. J. Blau and R. L. Martin, "Friction and wear of carbongraphite materials against metal and ceramic counterfaces," Tribology International, vol. 27, no. 6, pp. 413-422, 1994.

[9] S. Mori, P. Cong, Y. Shinden, and H. Nanao, "Tribochemical reactions and lubricating effects of fluorinated methanes for $\mathrm{Al}_{2} \mathrm{O}_{3}$ ceramic," Tribology Letters, vol. 17, no. 1, pp. 83-89, 2004.

[10] M. S. Phadke, Quality Engineering Using Design of Experiment, Quality Control, Robust Design and Taguchi Method, Warsworth \& Books, Belmont, Calif, USA, 1998.

[11] R. Ranjit, Design of Experiment Using the Taguchi Approach, John Wiley \& Sons, New York, NY, USA, 2001.

[12] A. I. Golubiev, "On the existence of a hydrodynamic film in mechanical seals," in Proceedings of International Conference on Fluid Sealing, Cambridge, UK, April 1967.

[13] F. Svahn, A. Kassman-Rudolphi, and S. Hogmark, "On the effect of surface topography and humidity on lubricated running-in of a carbon based coating," Wear, vol. 261, no. 1112, pp. 1237-1246, 2006.

[14] R. Holm, Electric Contacts Handbook, Springer, Berlin, Germany, 1958.

[15] G. Hockel, "Untersuchungen über Grenzreibung von Metallen und Gummi bei höheren Gleitgeschwindigkeiten," Konstruktion, vol. 7, pp. 394-404, 1955.

[16] J. K. Lancaster, "A review of the influence of environmental humidity and water on friction, lubrication and wear," Tribology International, vol. 23, no. 6, pp. 371-389, 1990.

[17] G. A. Jones, "On the tribological behaviour of mechanical seal face materials in dry line contact Part II. Bulk ceramics, diamond and diamond-like carbon films," Wear, vol. 256, no. 3-4, pp. 433-455, 2004.

[18] M. D. Bryant, J.-P. Wang, and J.-W. Lin, "Thermal mounding in high speed dry sliders: experiment, theory and comparison," Wear, vol. 181-183, part 2, pp. 668-677, 1995.

[19] J. F. Archard, "Contact and rubbing of flat surfaces," Journal of Applied Physics, vol. 24, no. 8, pp. 981-988, 1953.

[20] D. W. Wisander and R. L. Johnson, "Wear and friction on impregnated carbon seal materials in liquid nitrogen and hydrogen," in Proceedings of the International Conference on Advances in Cryogenic Engineering, Boulder, Colo, USA, June 1966. 

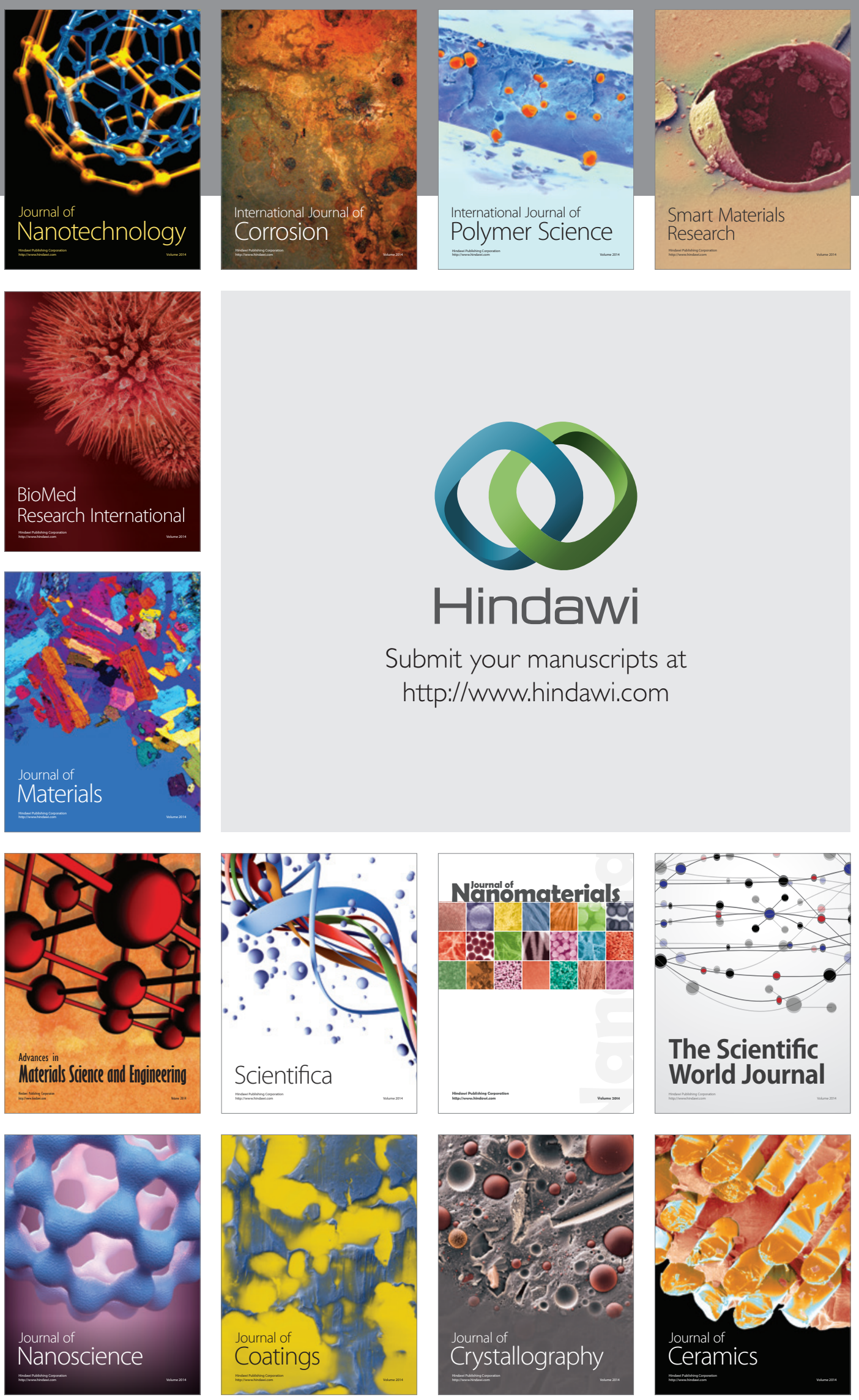

The Scientific World Journal

Submit your manuscripts at

http://www.hindawi.com

\section{World Journal}

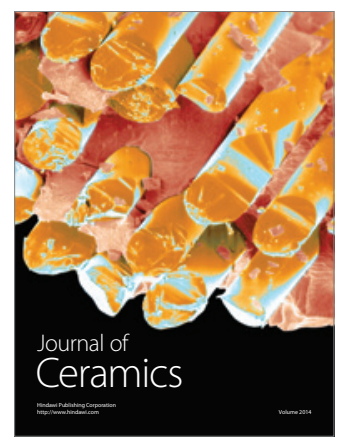

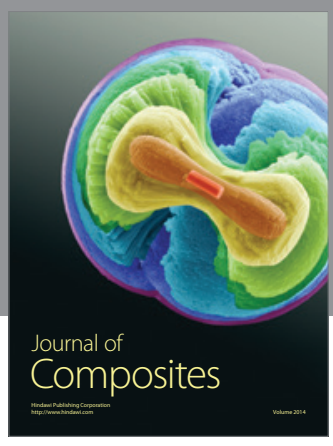
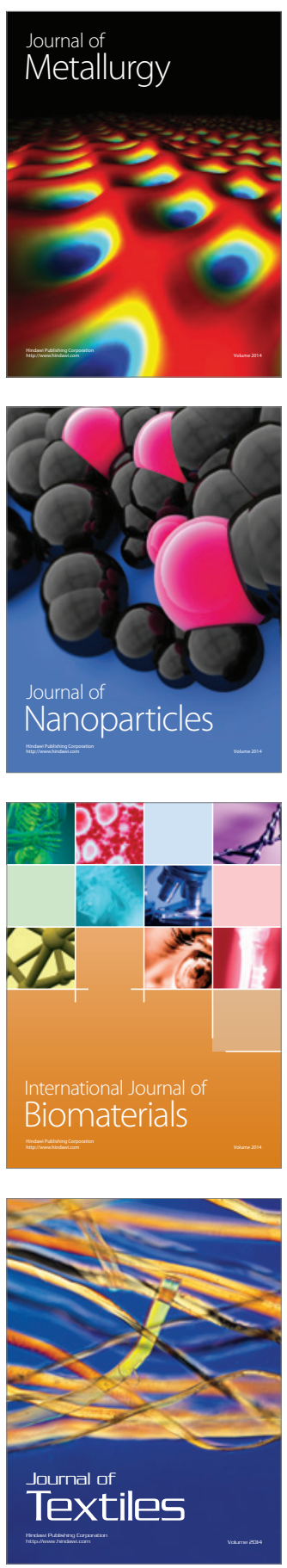